\title{
Bringing cooperation nearer
}

\begin{abstract}
A joint move backing planned European involvement with a major NASA space science project of the 1980s has come from the European Science Foundation and the US National Academy of Sciences. Allan Piper reports
\end{abstract}

Following a meeting between the European Science Foundation and the US National Academy of Sciences at Williamsburg in Virginia, it has become clear that the independent scientific community represented by the two organisations means to become involved in the new \$350-millions Large Space Telescope project (LST) planned for the 1980 s by NASA. Recommendations developed during the meeting particularly underline European interest in the telescope, already under consideration as a priority project in the European Space Agency's programme of cooperation with NASA.

The LST, planned as a 2-metre diffraction limited optical telescope, should be in orbit by the end of 1983 as part of NASA's forthcoming space shuttle programme. Essentially an advanced and updated version of the highly successful Copernicus telescope launched four years ago, it will be used in planetary, galactic and intergalactic studies. The planned payload includes instrumentation covering the entire optical spectrum from infrared to ultraviolet, providing astronomers with a first opportunity to obtain data which is not accessible from Earth-

\section{bound observatories.}

Described at Williamsburg as the single most important next step that could be taken in astronomy, the project hogged the spotlight during the wider debate on international cooperation on space observatories.

Recommendations resulting from the meeting call among other things for an independent, international LST Science Institute. An ESF-USNAS advisory committee is also suggested to oversee the selection of instruments for the telescope's scientific payload.

But while the recommendations outwardly stress the importance of independent scientific involvement, it is the implicit backing for ESA-NASA cooperation on the project which is more significant. None of the Williamsburg scientists was directly involved with the LST, but their statements, both space agencies have indicated, will weigh in decisions on the next moves.

Under the circumstances that could prove crucial. The project is running through heavy weather in the US, where Congress has just declined to approve NASA funding for 1977 in the absence of outside backing. The congressional coyness is seen as nothing more than a firm come-on to ESA, known to be close to throwing in its lot for a share of the price tag, but there is a very real danger that it will serve only to turn away a possibly faint-hearted suitor.

The problem is that Congressional and ESA decision-making are almost exactly six months out of phase. So even though there is confidence that Congress will give NASA the nod for 1978 funds if ESA adopts the project in the meantime, ESA officials who were in any case sceptical of the project's running power in competition with the other five possible cooperative space ventures will now have to be convinced additionally that it is not a complete non-starter.

Before losing heart, however, ESA can reflect that Congress may view the project more favourably once the present heavy expenditure on the space shuttle begins to run down. Moreover, there is still a glimmer of hope that the decision not to programme 1977 funds for the LST may be reversed. In the US the Congressional snub has brought a deluge of angry protest letters from astronomers and other interested scientists. There is little chance at this stage of additional funds, but Congress is holding open an option on internal reallocation.

Although the European astronomy community is not as well organised at an informal level as its American counterpart, the need for a tightly orchestrated campaign before, and not after, an ESA decision is widely recognised. Already there is European concern that ESA's option on the project will go by the board because of misguided views that it will not serve any immediate needs in astronomy over and above those provided by projects already in the pipeline, such as the Northern Hemisphere Observatory. It is at that level that the ESF Space Science Committee, which shares observers with ESA, will be most effective in pointing out that the LST offers new and unique possibilities, and is not just a superfluous bonus.

\section{COMECON}

THE new Five Year Plans of the Comecon member countries began this year, and according to the Comecon Committee on Scientific and Technical Cooperation, which met in Budapest in January, scientific cooperation will be largely devoted to research projects and problems "which cannot be solved by individual countries". These include power production, protection of metals against corrosion, increase of protein production, the comprehensive utilisation of timber, and the testing of new insecticides. Discussions will also take place on the establishment of an integrated system for the exchange of scientific and technical information which, if successfully implemented, could eli- minate uneconomical duplication of research.

Special emphasis is to be placed on research into energy resources ranging from lignite to nuclear power. The production and consumption of energy by the Comecon bloc is still steadily expanding: according to Nikolai Faddeev (USSR), the Secretary of Comecon, the nuclear power stations in the USSR and those built with Soviet assistance in Bulgaria, the GDR and Czechoslovakia now have an aggregate capacity of $7,500 \mathrm{MW}$, and by 1980 this figure will have risen to some $30,000 \mathrm{MW}$.

A $2,750 \mathrm{~km}$ pipeline from Orenburg to the western frontier of the Soviet Union will carry some 15,000 million $\mathrm{m}^{3}$ of gas per year from the Orenburg gas condensate deposit to Bulgaria, Hungary, the GDR, Romania and Czechoslovakia. The second string of the Druzhba oil pipeline from the Soviet Union has been completed, and in 1975 delivered some 50 million tons of oil. Joseph Zamparo, of the University of Genoa, addressing the Conference on Energy Alternatives sponsored by the American Nuclear Society, said that energy consumption of the Communist countries (including China) was increasing by an average of $6.5 \%$, whereas all other countries were reducing their energy consumption by amounts ranging from $9 \%$ for Western Europe to $2 \%$ for Australia. 